\title{
Comparison of cellular responses across multiple passage numbers in Ba/F3-BCR-ABL cells induced by silver nanoparticles
}

\author{
GUO DaWei ${ }^{1,2 \dagger}$, ZHANG XiuYan $^{3 \dagger}$, HUANG ZhiHai ${ }^{1,2}$, ZHOU XueFeng ${ }^{1,2}$, \\ ZHU LingYing ${ }^{1,2}$, ZHAO Yun ${ }^{3} \&$ GU Ning ${ }^{1,2^{*}}$ \\ ${ }^{1}$ Jiangsu Key Laboratory for Biomaterials and Devices, State Key Laboratory of Bioelectronics, School of Biological Science \& \\ Medical Engineering, Southeast University, Nanjing 210096, China; \\ ${ }^{2}$ Suzhou Key Laboratory of Biomedical Materials and Technology, Research Institute of Southeast University in Suzhou, \\ Suzhou 215123, China; \\ ${ }^{3}$ Cyrus Tang Hematology Center, Jiangsu Institute of Hematology, First Affiliated Hospital, Soochow University, Suzhou 215123, China
}

Received June 8, 2012; accepted September 10, 2012

\begin{abstract}
With the rapid development of nanotechnology and increasingly broad bio-application of engineered nanomaterials, their biohazards have become a serious public concern. It is believed that the chemical nature, particle size, morphology, and surface chemistry of nanomaterials are key parameters that influence their toxicity. Although cultured cells have been widely used to evaluate nanomaterial toxicity, it remains unclear whether the passage of these cells affects the evaluation results. In the present study, $\mathrm{Ba} / \mathrm{F} 3$ cells transfected with the $B C R$ - $A B L$ gene were subcultured to study the effect of passage number on cell stability and their cellular responses upon exposure to nanomaterials. The results demonstrated that proliferation, cellular senescence, $B C R-A B L$ gene expression, cell cycle and apoptosis were stable across multiple passages. Senescence and $B C R$ - $A B L$ gene expression of cells from different passage cells were unchanged when treated with silver nanoparticles (AgNPs). In addition, the cells at multiple passage numbers were all arrested in the $\mathrm{G}_{2} / \mathrm{M}$ phase and apoptosis was induced by the AgNPs. These nanoparticles could enter cells via endocytosis and localize in the endosomes, which were also not influenced by passage number. These data suggest that short-term passage would not affect cultured cell stability and toxicity assessment using these cells would be consistent when maintained appropriately.
\end{abstract}

silver nanoparticles (AgNPs), cellular response, cell passage, stability, uptake

Citation: $\quad$ Guo D W, Zhang X Y, Huang Z H, et al. Comparison of cellular responses across multiple passage numbers in Ba/F3-BCR-ABL cells induced by silver nanoparticles. Sci China Life Sci, 2012, 55: 898-905, doi: 10.1007/s11427-012-4382-Z

The potential adverse effects of nanomaterials have become a public concern as nanotechnologies have rapidly developed and various engineered nanomaterials are widely used [1]. It is well established that the chemical nature, particle size, morphology, and surface chemistry of nanomaterials are critical parameters that influence their biological toxicity $[2,3]$. In vitro cell culture has been routinely used for nanoparticle toxicity assessment to provide a useful and

$\dagger$ Contributed equally to this work

*Corresponding author (email: guning@ seu.edu.cn) relatively inexpensive result that could be subsequently re-examined in vivo [4]. However, a growing body of literature has demonstrated that excessive subculturing could disturb the properties of some cultured cells over time. Cells at high passage numbers experience alterations compared with those at lower passage numbers, including cell morphology, response to stimuli, growth rates, protein expression, and signaling [5-8]. Thus, a critical issue is whether the properties of the cells used in testing can be stably maintained through passages and whether their cellular re- 
sponse upon nanomaterial exposure is consistent enough to evaluate the toxicity of these newly developed agents.

The principal exposure routes of nanomaterials in humans are inhalation, ingestion, injection for therapeutic purposes, and dermal contact. Following exposure, nanoparticles can be transported to different internal organs of the body via blood or lymphatic circulation [9]. Therefore, it is important to understand the impact of nanomaterials on blood cells.

Widely commercialized silver nanoparticles (AgNPs) are commonly used in wound dressings, catheters, and various house-hold products because of their antimicrobial activity [10]. AgNPs also have multiple properties, such as anti-inflammation, anti-virus, anti-AIDS, anti-angiogenesis, and especially anti-cancer [11-17]. In contrast, several studies have shown that AgNPs have strong cytotoxic effects on normal human cells $[18,19]$. The potential applications of AgNPs in medicine are confronted with both opportunities and challenges.

In this study, immortalized murine pro-B $\mathrm{Ba} / \mathrm{F} 3$ cells transfected with the oncogenic $B C R-A B L$ gene $(\mathrm{Ba} / \mathrm{F} 3-$ BCR-ABL cells) were subcultured with multiple passage numbers to study the effects of passages on cell stability and the response to nanomaterial exposure. The proliferation, cellular senescence, $B C R-A B L$ expression, cell cycle status, and apoptosis of $\mathrm{Ba} / \mathrm{F} 3-\mathrm{BCR}-\mathrm{ABL}$ cells at various passages and their cellular response upon exposure to AgNPs were assessed. Our data have demonstrated that short-term passage did not affect the stability of the cells or their response to nanomaterial exposure, which suggests that an in vitro evaluation of nanomaterial cytotoxicity with appropriately cultured cells would be consistent.

\section{Materials and methods}

\subsection{Silver nanoparticle synthesis and characterizations}

In this study, silver nanoparticles (AgNPs) were synthesized by a continuous flow electrochemical process, in which only polyvinylpyrrolidone (PVP) and two silver rods were used as stable agents and electrodes, respectively. The PVP was of analytical grade and used without further purification, and the purity of the silver rods was $99.99 \%$. The typical synthesis process was as follows: first, the silver electrodes were polished with ultrafine carborundum paper, and then were fitted on the reactor's cover after being washed with absolute ethyl alcohol. Second, the electrolytic solution containing $5 \mathrm{mg} \mathrm{mL}^{-1}$ PVP was prepared and filled into the syringe. Subsequently, the electrolytic solution was injected continuously through the inlet tube of the reactor's cover into the reactor at a flow rate of $80 \mathrm{~mL} \mathrm{~h}^{-1}$. The reaction temperature was $60^{\circ} \mathrm{C}$, and the voltage of $15 \mathrm{~V}$ was applied to electrolyze the silver rods. During the reaction, the electrolytic solution was stirred with a magnetic rotor, and the current direction of the electrodes was alternately changed every minute. After the reactor was filled, the product flowed out of the outlet tube of the reactor's cover. Finally, the freeze-dried silver nanoparticle powder was obtained after filtration, centrifugation, and lyophilization. The morphologies of the silver nanoparticles were characterized by transmission electron microscopy (TEM) (JEM-2000EX, JEOL, Japan), and the size distribution of the silver nanoparticles was counted. The hydrodynamic diameter and zeta potential of the silver nanoparticles were characterized by dynamic light scattering (DLS) using a Malvern Zetasizer Nano (Malvern Instruments Ltd., Worcestershire, UK). The final silver concentration in the dispersion was determined by inductively coupled plasma mass spectrometry (ICP-MS).

\subsection{Construction and subculture of $\mathrm{Ba} / \mathrm{F3}-\mathrm{BCR}-\mathrm{ABL}$ cells}

$\mathrm{Ba} / \mathrm{F} 3$ cells are from an immortalized murine bone marrow-derived pro-B cell line, whose growth and proliferation depend upon the presence of murine interleukin-3 (mIL-3). However, when the $\mathrm{Ba} / \mathrm{F} 3$ cells were stably transfected with p210 ${ }^{B C R-A B L}$, the cells could proliferate without mIL-3 [20]. It was expected that a freeze-thaw cycle was a passage of suspended cells. The time from recovery to a frozen state must be more than three days, and the time from a frozen state to recovery must be more than one day. Ba/F3-BCRABL cells from the 1st, 10th, and 20th passages (P1, 10, and P20 cells) were used to study cell stability and the response to nanomaterial exposure. All of the cells were cultured with RPMI 1640 (Hyclone, USA) plus 10\% fetal bovine serum (FBS, Hyclone) in an incubator with a humidified atmosphere of $5 \% \mathrm{CO}_{2}$ at $37^{\circ} \mathrm{C}$.

\subsection{Cell proliferation}

The cells were cultured in 24-well tissue culture plates at an initial density of $2 \times 10^{4}$ cells $\mathrm{mL}^{-1}$. The cell numbers were counted by a trypan blue exclusion assay.

\subsection{Detection of senescence}

The $\mathrm{Ba} / \mathrm{F} 3-\mathrm{BCR}-\mathrm{ABL}$ cells were fixed and stained to detect SA $\beta$-gal activity with a Senescence $\beta$-Galactosidase Staining Kit (Beyotime Institute of Biotechnology, China). The percentage of SA $\beta$-gal positive cells (blue cells) was determined by counting at least 200 total cells.

\section{5 $B C R-A B L$ gene expression by quantitative RT-PCR}

Total RNA was extracted from the Ba/F3-BCR-ABL cells with RNAiso Plus (Takara, Shiga, Japan) and quantified with a NanoDrop 2000 Spectrophotometer (Thermo Scientific, USA). The reverse transcription reactions were performed using PrimeScript RT Master Mix (Perfect Real 
Time, Takara). The newly synthesized cDNA was amplified with SYBR Premix Ex Taq ${ }^{\mathrm{TM}}$ II (Perfect Real Time, Takara) with the ABI 7500 Real-Time PCR System (Applied Biosystems, Foster City, CA, USA). The primers used were as follows: $B C R-A B L$ primers (forward: 5'-CATTCCGCTGACCATCAATAAG-3', reverse: 5'-GATGCTACTGGCCGCTGAAG-3') and $\beta$-actin primers (forward: 5'-AACAGTCCGCCTAGAAGCAC-3', reverse: 5'-CGTTGACATCCGTAAAGACC- $3^{\prime}$ ). The reaction conditions were $90^{\circ} \mathrm{C}$ for 30 $\mathrm{s}$ and 40 cycles of $95^{\circ} \mathrm{C}$ for $5 \mathrm{~s}, 60^{\circ} \mathrm{C}$ for $31 \mathrm{~s}$. Each experiment was performed in triplicate. Relative quantification of the target transcripts from the $\mathrm{Ba} / \mathrm{F} 3-\mathrm{BCR}-\mathrm{ABL}$ cells at multiple passage numbers that were AgNP-treated or untreated was determined by quantitative RT-PCR and calculated using SDS software based on the $\Delta \Delta \mathrm{Ct}$ method with $\beta$-actin as the endogenous control for normalization.

\subsection{Uptake of silver nanoparticles (ICP-MS)}

Cells at multiple passage numbers were exposed to $12 \mu \mathrm{g}$ $\mathrm{mL}^{-1}$ AgNPs for $24 \mathrm{~h}$, and then washed three times with PBS. An equivalent number $\left(1 \times 10^{6}\right)$ of cells were digested with $64 \%$ nitric acid in an electric stove for $15 \mathrm{~min}$. The silver concentration was determined by ICP-MS.

\subsection{Intracellular localization of silver nanoparticles (TEM)}

The cells were cultured in 100-mm tissue culture dishes followed by AgNPs treatment. For the control experiments, medium without nanoparticles was used. After 24-h incubation, the cell pellets were washed with PBS, and then fixed with $2.5 \%$ glutaraldehyde in PBS for $24 \mathrm{~h}$, which was followed by post-fixation in $1 \%$ osmium tetroxide (Agar Scientific, Stansted, UK) for $1.5 \mathrm{~h}$. The cell pellets were dehydrated through a series of ethanol concentrations $(20 \%, 30 \%, 40 \%, 50 \%, 60 \%, 70 \%$, and $90 \%)$, followed by a treatment with $2 \%$ uranyl acetate in $95 \%$ ethanol (en bloc stain) for $1 \mathrm{~h}$ and further dehydration with $100 \%$ ethanol for $1 \mathrm{~h}$. The cell pellets were finally treated with propylene oxide (twice for $15 \mathrm{~min}$ each), followed by an overnight treatment with $1: 1$ propylene oxide: araldite resin, that was infiltrated with fresh araldite resin (3 changes with a 3- to 4-h interval), and subsequently embedded in araldite resin at $60^{\circ} \mathrm{C}$ for $48 \mathrm{~h}$. Ultra-thin sections were cut with glass knives in an ultra microtome (LEICA EM UC6, The Netherlands). The sections were mounted on copper grids and stained with $1 \%$ aqueous uranyl acetate and $0.2 \%$ lead citrate. The stained sections were scanned by TEM (JEM-2000EX, JEOL) for ultra structural observations at $80 \mathrm{kV}$.

\subsection{Cell viability}

Cell viability was measured using a Cell Counting Kit- 8
(CCK-8) according to the manufacturer's instructions with the appropriate controls. The cells were seeded in 96-well microtiter plates $\left(1 \times 10^{4}\right.$ cells $/ 200 \mu \mathrm{L}$ culture medium/well $)$ with AgNPs at multiple concentrations. Briefly, $24 \mathrm{~h}$ later, a CCK-8 solution was added to each well, and the cells were incubated for $4 \mathrm{~h}$. Subsequently, the absorbance at two wavelengths ( $450 \mathrm{~nm}$ for the soluble dye and $650 \mathrm{~nm}$ for the viable cells) was detected using a microplate reader (SpectraMax M5, Molecular Devices, Sunnyvale, CA, USA).

\subsection{Apoptosis assay}

For the annexin V-FITC/propidium iodide (PI) assays, the cells were stained and analyzed for apoptosis by flow cytometry according to the manufacturer's protocol. Briefly, $1 \times 10^{5}$ cells were stained with $5 \mu \mathrm{L}$ annexin V-FITC and 5 $\mu \mathrm{L}$ PI $\left(5 \mu \mathrm{g} \mathrm{mL}^{-1}\right)$ for $20 \mathrm{~min}$ at room temperature in the dark. The apoptotic/necrotic cells were determined by flow cytometry using a FACSCalibur (Becton-Dickinson).

\subsection{Cell cycle assay}

Cell cycle analysis was performed by measuring the DNA content of the treated and untreated cells by flow cytometry. The cells were cultured in 100-mm tissue culture dishes followed by an AgNPs treatment for $24 \mathrm{~h}$. Subsequently, the cells were washed with PBS, fixed by slowly adding $2 \mathrm{~mL}$ of pre-chilled $70 \%$ ethanol, and finally stored at $4{ }^{\circ} \mathrm{C}$ overnight. The following day, the cells were washed with ice-cold PBS and were incubated in RNase A $\left(100 \mu \mathrm{g} \mathrm{mL}^{-1}\right)$ at $37^{\circ} \mathrm{C}$ for $30 \mathrm{~min}$, which was followed by staining with PI $\left(40 \mu \mathrm{g} \mathrm{mL}^{-1}\right)$ at $4^{\circ} \mathrm{C}$ for $30 \mathrm{~min}$ in the dark. Immediately after staining, the samples were analyzed with a FACSCalibur (Becton-Dickinson), and the data were re-analyzed with FlowJo software (Tree Star, Ashland, OR, USA).

\subsection{Statistical analysis}

A statistical analysis of the obtained data was performed using SPSS software (version 16.0), and all of the values were represented as the means \pm SD of more than three independent experiments. The results were subjected to one-way ANOVA using Duncan's test to analyze the difference between the treated and untreated groups, in which a $P$-value less than 0.05 was considered significantly different.

\section{Results}

\subsection{Nanoparticles characterization}

Silver nanoparticles used in the present study were readily synthesized by a continuous flow electrochemical method using polyvinylpyrrolidone (PVP) as a capping agent. The 
results of the TEM illustrated that the typical morphologies of AgNPs approximated spheres and were uniform, and the average size was $29.7 \mathrm{~nm}$ (Figure $1 \mathrm{~A}$ and $\mathrm{B}$ ). The UV-Vis spectrum also demonstrated that the obtained AgNPs were highly mono-dispersed because the absorbance peaks were sharp (Figure 1C). The average hydrodynamic diameter and zeta potential $(\zeta)$ of the AgNPs in an aqueous solution were $(70.0 \pm 1.32) \mathrm{nm}$ and $(-23.0 \pm 1.01) \mathrm{mV}$, respectively, as determined by dynamic light scattering (DLS) (Figure 1D and E).

\subsection{Proliferation}

Our data have demonstrated that $\mathrm{Ba} / \mathrm{F} 3-\mathrm{BCR}-\mathrm{ABL}$ cell proliferation was unchanged among the 1st, 10th and 20th passages, which indicated that cell proliferation was unaffected by short-term passage (Figure 2).
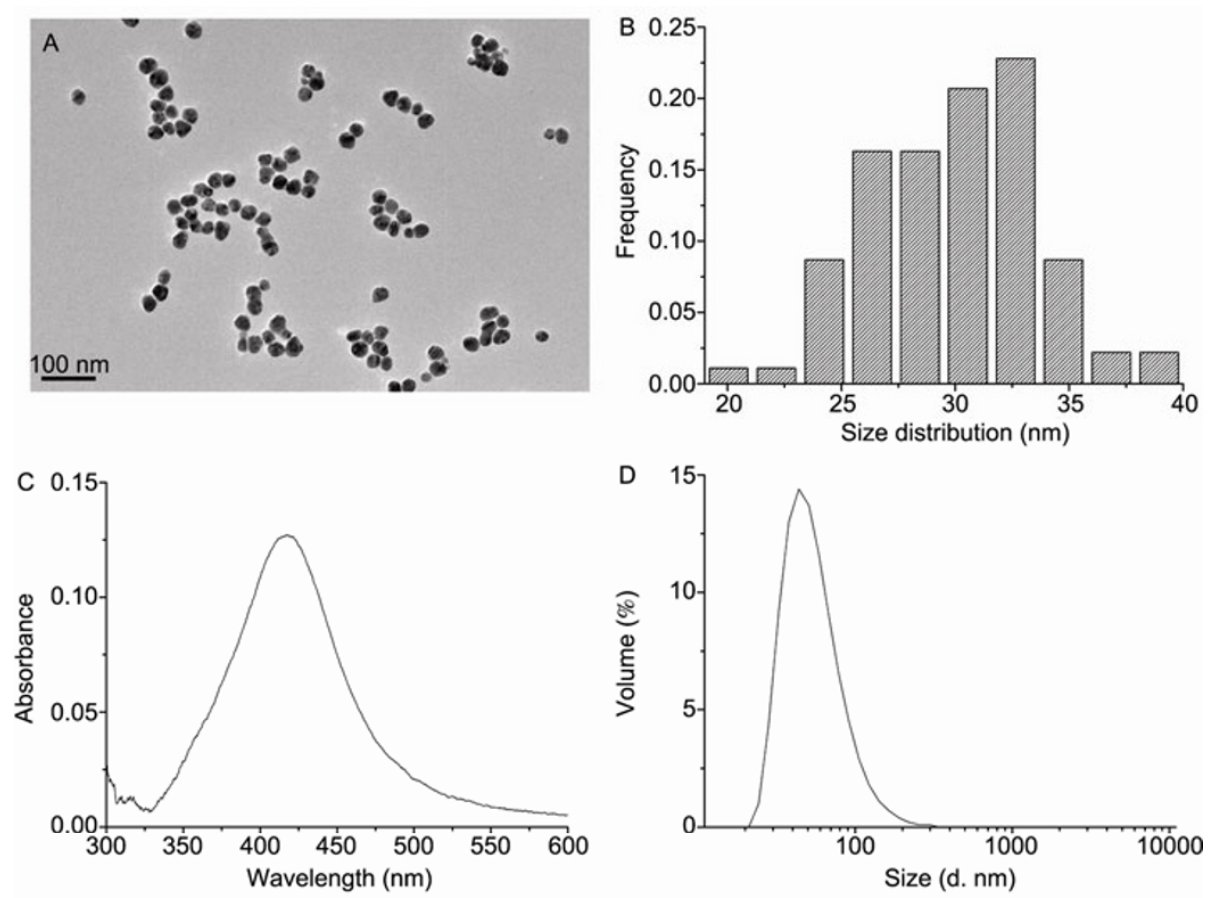

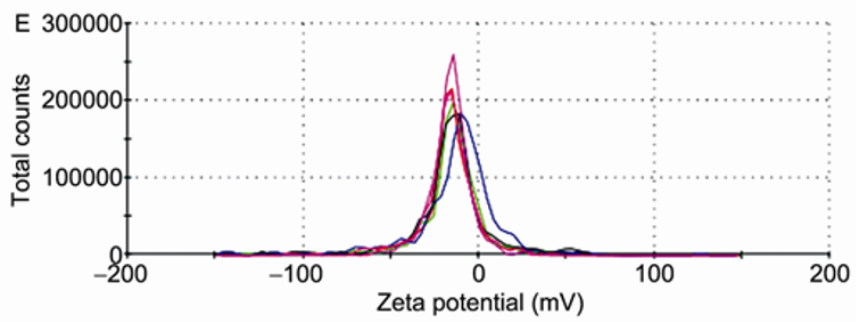

Figure 1 Characterization of silver nanoparticles. A and B, The morphology and size distribution of the silver nanoparticles were characterized by transmission electron microscopy (TEM). The mean diameter was $29.7 \mathrm{~nm}$. C, The AgNPs were characterized by the UV-Vis absorption spectrum, and the maximum absorption was $417 \mathrm{~nm}$. D and E, Particles size (diameter) and surface charge in an aqueous solution were measured by dynamic light scattering (DLS) and were $(71.83 \pm 0.74) \mathrm{nm}$ and $(-23.0 \pm 1.01) \mathrm{mV}$, respectively. 


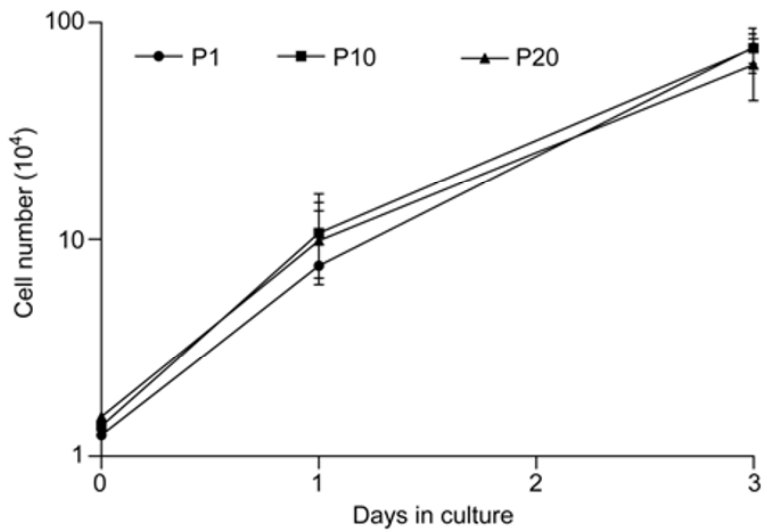

Figure $2 \mathrm{Ba} / \mathrm{F} 3-\mathrm{BCR}-\mathrm{ABL}$ cell proliferation at multiple passage numbers. The cell numbers were compared among cells at multiple passage numbers by the trypan blue exclusion method. P1, P10 and P20 denote the $\mathrm{Ba} / \mathrm{F} 3-\mathrm{BCR}-\mathrm{ABL}$ cells at the 1 st, 10th and 20th passages, respectively.

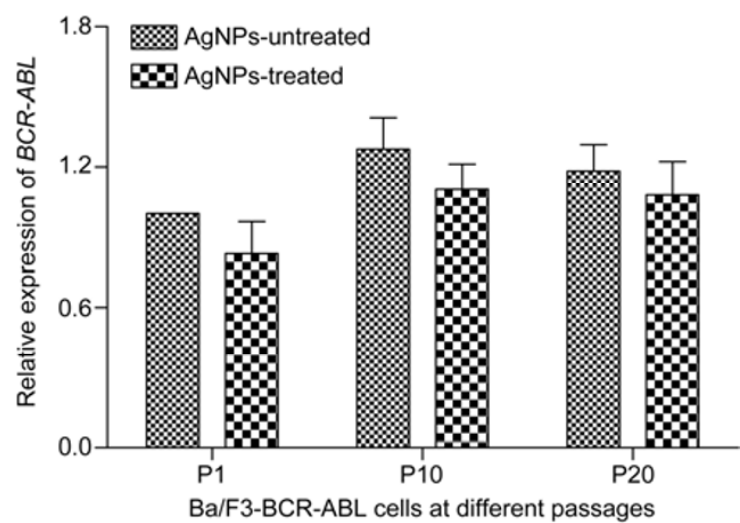

Figure $3 \quad B C R-A B L$ gene expression. $B C R-A B L$ expression of the $\mathrm{Ba} / \mathrm{F} 3-$ BCR-ABL cells at multiple passage numbers that were AgNPs-treated or untreated was determined by quantitative RT-PCR. strated that the relative expression of $B C R-A B L$ gene of the $\mathrm{Ba} / \mathrm{F} 3-\mathrm{BCR}-\mathrm{ABL}$ cells was not significantly different among the different passage numbers and between the AgNP-treated and untreated cells (Figure 3).

\subsection{Cellular uptake of AgNPs}

The cellular uptake of AgNPs was detected quantitatively by ICP-MS. The results demonstrated that the uptake efficiency of AgNPs was similar among cells at multiple passage numbers (Figure 4B).

\subsection{Intracellular localization of AgNPs}

The cellular entry pathway and localization varied with the characteristic of the nanoparticles. Even identical nanoparticles had different entry pathways and intracellular localization across different cell types. The intracellular localization of the nanoparticles further determined their biological effects. Herein, TEM was employed to analyze the localization of the AgNPs in the cells at multiple passage numbers. It was shown that AgNPs were localized in the endosomes of the cells at all passage numbers (Figure 4A).

\subsection{Cell viability}

The viability of $\mathrm{Ba} / \mathrm{F} 3-\mathrm{BCR}-\mathrm{ABL}$ cells after a $24-\mathrm{h}$ exposure to AgNPs was determined with a CCK-8 assay, which was inhibited by AgNPs in a dose-dependent manner (Figure 5). In addition, there was no difference in the dosedependent inhibition among cells at different passages.

\subsection{Apoptosis/necrosis}

$\mathrm{Ba} / \mathrm{F} 3-\mathrm{BCR}-\mathrm{ABL}$ cells at multiple passage numbers were
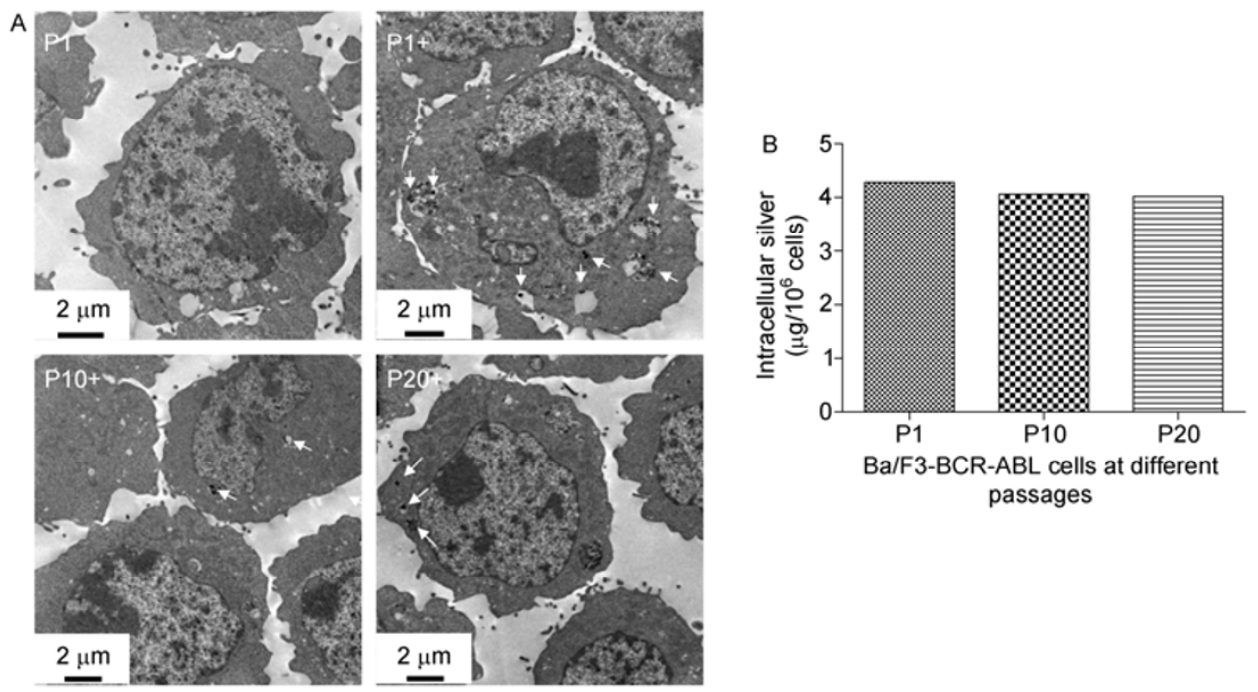

Figure 4 Uptake and localization of AgNPs in Ba/F3-BCR-ABL cells at multiple passage numbers. A, TEM images of ultrathin sections of $\mathrm{Ba} / \mathrm{F} 3-\mathrm{BCR}-\mathrm{ABL}$ cells treated with AgNPs $\left(12 \mu \mathrm{g} \mathrm{mL}^{-1}\right)$ for $24 \mathrm{~h}$ showed that the particles were internalized and could be sequestered in vacuoles, which were visible in the cells as black, and the electron-dense spots are indicated by arrows. B, The cells treated with AgNPs $\left(12 \mu \mathrm{g} \mathrm{mL} \mathrm{m}^{-1}\right)$ for $24 \mathrm{~h}$ were digested in nitric acid, and the silver concentration was determined by ICP-MS. "+" denotes that cells were treated with AgNPs. 


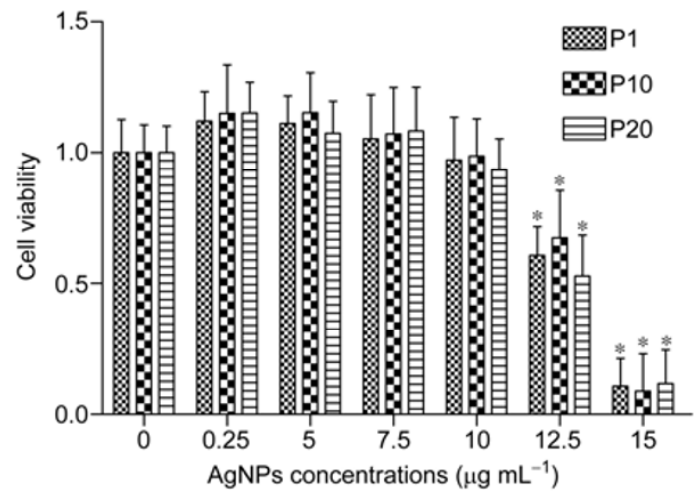

Figure 5 Effects of AgNP exposure on Ba/F3-BCR-ABL cell viability at multiple passage numbers. After a 24-h exposure of AgNPs at multiple concentrations, cell viability was determined with a Cell Counting Kit- 8 (CCK-8). The data were a summary of three independent experiments and expressed as the means $\pm \mathrm{SD} . *$ denotes a significant reduction in cell viability $(P<0.05)$ compared with the control.

double-stained with annexin V-FITC and propidium iodide, and apoptosis/necrosis was then analyzed by flow cytome- try. The results demonstrated that the apoptosis level was unaffected by the passage. After a 24-h treatment with 10 $\mu \mathrm{g} \mathrm{mL}{ }^{-1}$ AgNPs, the apoptosis/necrosis level had not significantly increased, which suggests that cells at different passage numbers had similar sensitivity to AgNP exposure (Figure 6A and B). Using the 1st passage cells, we determined that AgNPs induced cell apoptosis/necrosis in a dose-dependent manner (Figure 6C and D).

\subsection{Cell cycle}

The effect of AgNPs on the cell cycle was also analyzed by flow cytometry, and we determined that cells at all passages were at similar cell cycles. After a 24-h treatment with10 $\mu \mathrm{g}$ $\mathrm{mL}^{-1}$ AgNPs, the cells at all passages were uniformly arrested in the $G_{2} / M$ phase (Figure $7 A$ and $B$ ). Cell cycle status and their sensitivity to AgNP exposure were unaffected by the passage. In addition, AgNP exposure distorted cell cycle distributions in a dose-dependent manner (Figure 7C and D).
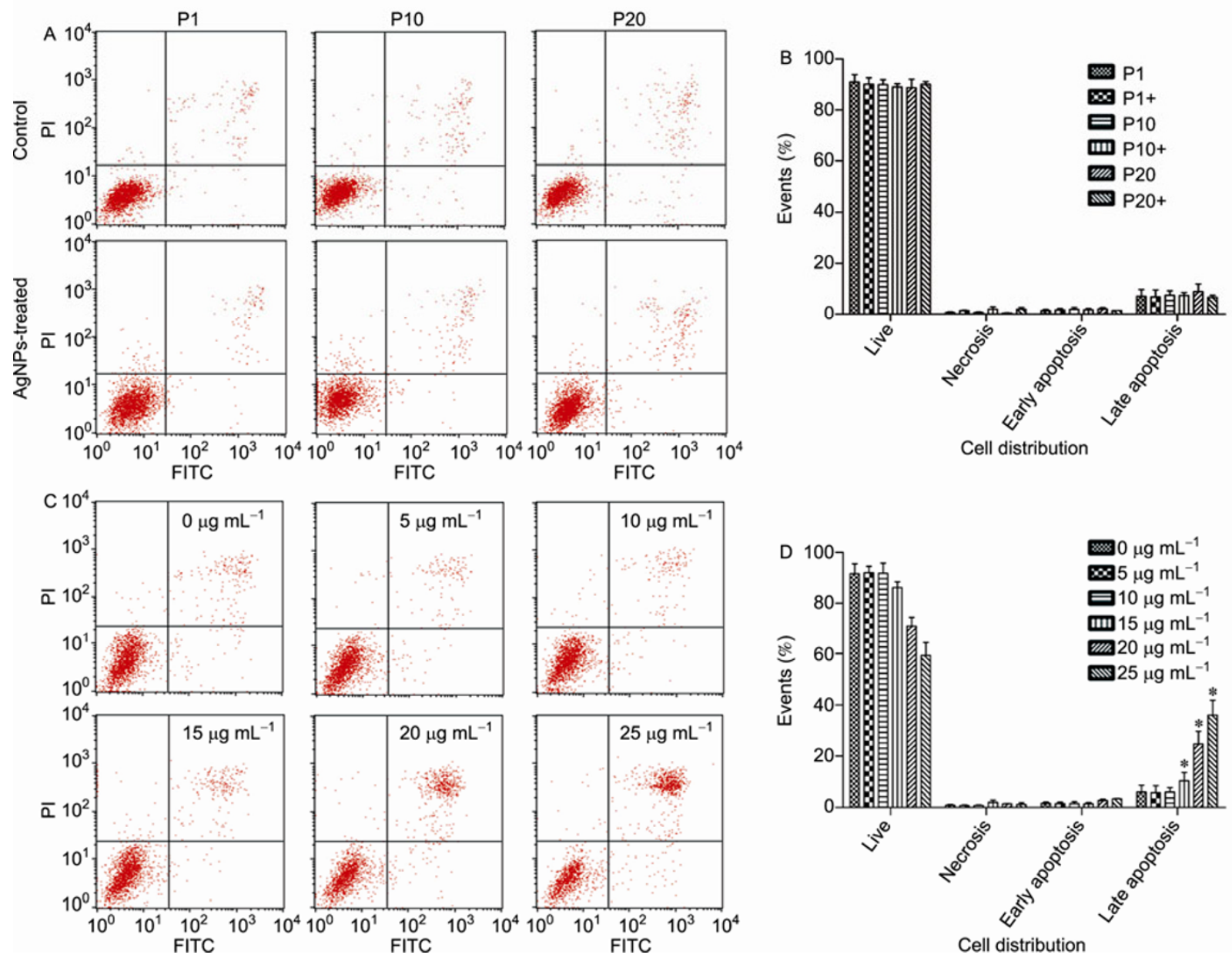

Figure 6 Effect of passage number and AgNP exposure on apoptosis of Ba/F3-BCR-ABL cells. A and B, The representative images and summaries of apoptosis of the AgNP-treated $\left(10 \mu \mathrm{g} \mathrm{mL}^{-1}\right)$ and untreated Ba/F3-BCR-ABL cells at multiple passage numbers are presented. $\mathrm{C}$ and $\mathrm{D}$, The representative images and summaries of apoptosis of the 1st passage Ba/F3-BCR-ABL cells induced by AgNP exposure at various concentrations are presented. 

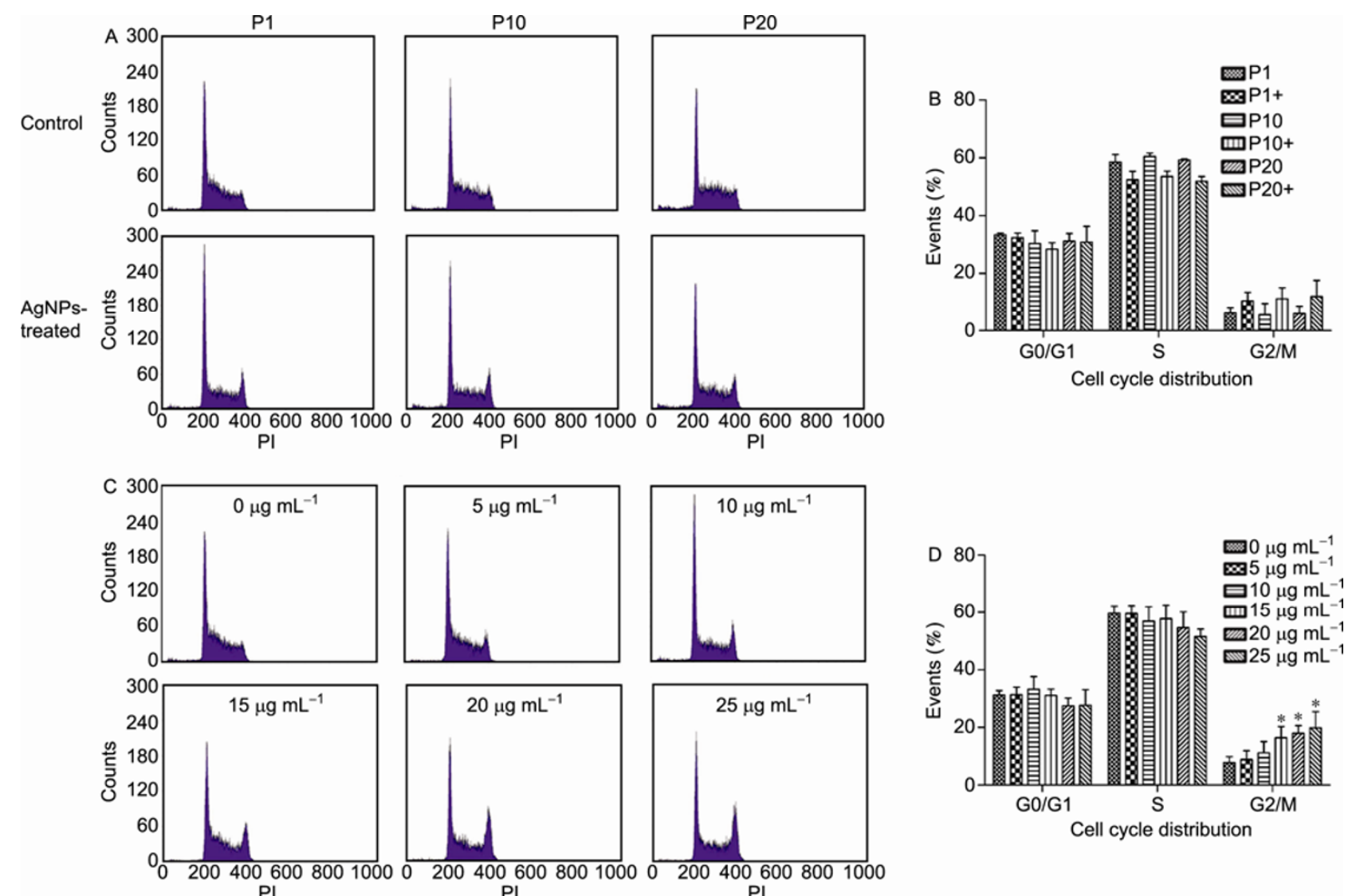

Figure 7 Effect of passage number and AgNP exposure on the cell cycle of Ba/F3-BCR-ABL cells. A and B, The representative images and summaries of the cell cycle of the AgNP-treated $\left(10 \mu \mathrm{g} \mathrm{mL}^{-1}\right)$ and untreated Ba/F3-BCR-ABL cells at multiple passage numbers are presented. C and D, The representative images and summaries of the cell cycle of the 1st passage Ba/F3-BCR-ABL cells induced by AgNP exposure at various concentrations are presented.

\section{Discussion}

Both nanomaterial properties and cultured cell features can influence the results of toxicity measurements. Compared to the nanomaterials, there are more cultured cell factors that could affect the toxicity assessment, among which the passage number is a significant one. For some types of cells, excessive subculturing can disturb their properties. To obtain consistent toxicity test results, it is critical to carefully evaluate whether passage numbers can alter the properties of the cells used in toxicity testing and whether their cellular response to nanomaterial exposure is consistent. To our knowledge, systematic studies regarding whether passage numbers could affect the stability of cultured cells and their response to the nanomaterial exposure has not been available. Nevertheless, in addition to passage numbers, there are other parameters that could affect cultured cell properties. Investigating the potential impact of other factors on cultured cells and their response to nanomaterial exposure is of future interest.

Our results have demonstrated that cultured cells could retain their biological properties when maintained appropriately, and the passage itself would not affect the cellular response to nanomaterial exposure. Thus, toxicity assess- ment with such cultured cells could provide consistent results. In general, the careful selection of cultured cells that are stable in culture for long periods is essential for toxicity assessment. It is also important for laboratories to have cells from multiple normal tissues instead of immortalized carcinoma cells to evaluate the effect of nanomaterial exposure on multiple types of cells. Finally, establishing standard protocols to provide cross-laboratory comparisons among multiple research laboratories and institutions with cultured cells will facilitate nanomaterial applications.

This work was supported by the National Key Basic Research Program of China (Grant Nos. 2011CB933500 and 2011CB933501), the National Natural Science Foundation of China (Grant Nos. 60725101 and 50872021), the International Cooperation Program awarded by MOST (Ministry of Science and Technology) of China (Grant No. 2008DFA51180), the Natural Science Foundation of Jiangsu Province in China (Grant Nos. SBE201077305, BK2009013 and BK2009592), the Graduate Research and Innovation Program of Jiangsu Province in China (Grant No. CXZZ-0172), and a Project Funded by the Priority Academic Program Development of Jiangsu Higher Education Institutions.

1 Ahamed M, Alsalhi M S, Siddiqui M K. Silver nanoparticle applications and human health. Clin Chim Acta, 2010, 411: 1841-1848

2 Yang H, Liu C, Yang D, et al. Comparative study of cytotoxicity, 
oxidative stress and genotoxicity induced by four typical nanomaterials: the role of particle size, shape and composition. J Appl Toxicol, 2009, 29: 69-78

3 Yang X, Gondikas A P, Marinakos S M, et al. Mechanism of silver nanoparticle toxicity is dependent on dissolved silver and surface coating in Caenorhabditis elegans. Environ Sci Technol, 2012, 46: 1119-1127

4 Fischer H C, Chan W C. Nanotoxicity: the growing need for in vivo study. Curr Opin Biotechnol, 2007, 18: 565-571

5 Briske-Anderson M J, Finley J W, Newman S M. The influence of culture time and passage number on the morphological and physiological development of Caco-2 cells. Proc Soc Exp Biol Med, 1997, 214: 248-257

6 Chang-Liu C M, Woloschak G E. Effect of passage number on cellular response to DNA-damaging agents: cell survival and gene expression. Cancer Lett, 1997, 113: 77-86

$7 \mathrm{Yu} \mathrm{H}$, Cook T J, Sinko P J. Evidence for diminished functional expression of intestinal transporters in Caco-2 cell monolayers at high passages. Pharm Res, 1997, 14: 757-762

8 Sambuy Y, De Angelis I, Ranaldi G, et al. The Caco-2 cell line as a model of the intestinal barrier: influence of cell and culture-related factors on Caco-2 cell functional characteristics. Cell Biol Toxicol, 2005, 21: 1-26

9 Park J, Lim D H, Lim H J, et al. Size dependent macrophage responses and toxicological effects of $\mathrm{Ag}$ nanoparticles. Chem Commun (Camb), 2011, 47: 4382-4384

10 Johnston H J, Hutchison G, Christensen F M, et al. A review of the in vivo and in vitro toxicity of silver and gold particulates: particle attributes and biological mechanisms responsible for the observed toxicity. Crit Rev Toxicol, 2010, 40: 328-346
11 Shin, S H, Ye M K, Kim H S, et al. The effects of nano-silver on the proliferation and cytokine expression by peripheral blood mononuclear cells. Int Immunopharmacol, 2007, 7: 1813-1818

12 Lu L, Sun R W, Chen R, et al. Silver nanoparticles inhibit hepatitis B virus replication. Antivir Ther, 2008, 13: 253-262

13 Elechiguerra J L, Burt J L, Morones J R, et al. Interaction of silver nanoparticles with HIV-1. J Nanobiotechnol, 2005, 3: 6

14 AshaRani P V, Low Kah Mun G, Hande M P, et al. Cytotoxicity and genotoxicity of silver nanoparticles in human cells. ACS Nano, 2009, 3: $279-290$

15 Nallathamby P D, Xu X H. Study of cytotoxic and therapeutic effects of stable and purified silver nanoparticles on tumor cells. Nanoscale, 2010, 2: 942-952

16 Sriram M I, Kanth S B, Kalishwaralal K, et al. Antitumor activity of silver nanoparticles in Dalton's lymphoma ascites tumor model. Int J Nanomedicine, 2010, 5: 753-762

17 Gurunathan S, Lee K J, Kalishwaralal K, et al. Antiangiogenic properties of silver nanoparticles. Biomaterials, 2009, 30: 6341-5350

18 Greulich C, Diendorf J, Simon T, et al. Uptake and intracellular distribution of silver nanoparticles in human mesenchymal stem cells. Acta Biomater, 2011, 7: 347-354

19 Piao M J, Kang K A, Lee I K, et al. Silver nanoparticles induce oxidative cell damage in human liver cells through inhibition of reduced glutathione and induction of mitochondria-involved apoptosis. Toxicol Lett, 2011, 201: 92-100

20 Canitrot Y, Lautier D, Laurent G, et al. Mutator phenotype of BCR-ABL transfected $\mathrm{Ba} / \mathrm{F} 3$ cell lines and its association with enhanced expression of DNA polymerase beta. Oncogene, 1999, 18: 2676-2680

Open Access This article is distributed under the terms of the Creative Commons Attribution License which permits any use, distribution, and reproduction in any medium, provided the original author(s) and source are credited. 